\title{
Comparative analysis of city planning and land use change in Bangkok, Thailand, by using remote sensing and GIS
}

\author{
Suvimon Posuk ${ }^{1}$, Prof. Yoshitaka Kajita ${ }^{1}$, and Arthit Petchsasithon ${ }^{2, *}$ \\ ${ }^{1}$ Civil Engineering Department, Faculty of Engineering, Tokai University, Kanagawa, Japan \\ ${ }^{2}$ Civil Engineering Department, Faculty of Engineering, King Mongkut's Institute of Technology Ladkrabang, Bangkok, Thailand
}

\begin{abstract}
This study proposed the comparative analysis of city planning and land use change by using remote sensing and GIS in Bangkok, Thailand. Bangkok had been developed and faced many land use problems. If the problems were not controlled, it will cause more problems in the future. Therefore, this study suggested the solution to solve occurring land use problems in Bangkok. Which, remote sensing was used to do the land survey and automatically map urban land cover from Landsat time-series satellite imagery. Then, the change of urban area and Bangkok Comprehensive Plan were compared by GIS. And, the results showed that urban area in Bangkok increased $403.99 \mathrm{~km}^{2}$ over the past 21 years. While rural and agricultural zone in Bangkok Comprehensive Plan decreased due to residential area expansion. So, Area Division System and the district plan from urban planning system of Japan can solve the problems by developing the city and controlling urban areas expansion.
\end{abstract}

\section{Introduction}

Bangkok had been developed to be center of country and center of ASEAN Economic Community (AEC). Now, Bangkok has been faced unsuitable land use usage, flood prevention system, the disorder of urban area and environment problems [7]. If the land use change was not controlled, improved and planned, it will cause a lot of problems in future. Effective urban land use planning can help guide urban development. Also, Land survey is one of the processes that used for study land usage. Remote sensing can classify object from satellite imagery and can effective analyses time-series image. And, these techniques can be grouped into two types: (1) classification of input data and (2) directly segmenting the indices [2].

The objective of this study is to use remote sensing doing the land survey by applying Built-up Index (BUI), which has accuracy's result at $92.6 \%$ [8], to automatically map urban land cover from Landsat timeseries satellite imagery. Then, to compare the change of urban area with established Bangkok Comprehensive Plan (land use zoning plan) by using Geographic Information Systems (GIS). Last, this study suggests the solution to solve occurring land use problems in Bangkok from the successful land use plan.

\section{Study Area}

The study area is Bangkok City, Thailand. Bangkok located in the central region of the country and the total area is $1,568.74 \mathrm{~km}^{2}$, which is surrounding with six provinces and south part of the city is connected to the

\footnotetext{
" Corresponding author: arthit.pe@kmitl.ac.th
}

Gulf of Thailand. The approximate population is 5.69 million and population density is 3,629 people $/ \mathrm{km}^{2}$ (2014).

\section{Data Resources}

Time-series Landsat imagery was used in this study, which according to an established year or close to an established year of the Bangkok Comprehensive Plan. The Images have been downloaded from the U.S. Geological Survey. The images had area covering center region of Thailand that included all over the study area. Bangkok Comprehensive Plans have been downloaded from Department of Public Works and Town \& Country Planning. Bangkok city and Bangkok administrative zone have been downloaded from BMA GIS center. The materials used in this study are listed in Table 1.

Table 1. Information of materials used in this study.

\begin{tabular}{|c|c|}
\hline Data types & Year \\
\hline \multicolumn{2}{|c|}{ Satellite imagery } \\
\hline \multirow{4}{*}{ Landsat $5(\mathrm{TM})$} & 1993-11-07 \\
\hline & $1999-12-26$ \\
\hline & 2006-10-26 \\
\hline & 2006-12-29 \\
\hline Landsat $8(\mathrm{OLI})$ & 2014-11-17 \\
\hline \multicolumn{2}{|c|}{ Maps } \\
\hline Bangkok Administrative Zone & 2014 \\
\hline Bangkok Comprehensive Plan & $\begin{array}{llll}1992 & 1999 & 2006 & 2013 \\
\end{array}$ \\
\hline
\end{tabular}




\section{Methodology}

\subsection{The application of urban area extraction}

The Built-up Index (BUI) was applied for urban area extraction, which used the difference between NDVI and NDBI [8]. However, the river needs to be excluded by using the stream space information of the area, because BUI is very irregular and has a negative effect [3]. Therefore, the Modified Normalized Difference Water Index (MNDWI) was used to extract open water area to reduce the negative effect from BUI. The equation of the applications is showed as follows:

Urban area extraction $=B U I-M N D W I$

Built-up Index $=N D B I-N D V I$

NDVI $=($ Near Infrared - Red $) /$ (Near Infrared + Red)

NDBI = (Short-wave Infrared 1 - Near Infrared $) /$ (Short-wave Infrared $1+$ Near Infrared)

MNDWI = (Green - Short - wave Infrared 1) / (Green + Short-wave Infrared 1)

\subsection{Analyzed established Bangkok Comprehensive Plan}

Established Bangkok Comprehensive Plans Act. were analyzed to study the objectives, policies and promoted plans. Land Use Zoning Plan maps, which planned to control land use in Bangkok area, were digitized to GIS database map by using ArcMap 10.4.1 and were summarized to compare land use zoning plan change.

\subsection{Urban area and Bangkok Comprehensive Plan change analysis and study city problems solving solutions}

Urban area extraction results and urban growth causes [1] were summarized to define urban growth direction and were analyzed with Land Use Zoning Plan to do change analysis during an established period of Bangkok Comprehensive Plan, which compared the existing urban area with land use plan. Results of the analysis were considered the effect of city planning. Then, the solution of city planning problems was suggested by the study of concepts from successful land use plan.

\section{Results}

\subsection{Urban area automatic extraction}

Urban area in Bangkok increased in huge value over the past 21 years from $462.40 \mathrm{~km}^{2}$ in 1993 to $866.39 \mathrm{~km}^{2}$ in 2014 (403.99 $\mathrm{km}^{2}$ increased). The most changed urban area was between 1999 and 2006, which total urban area changed from $579.55 \mathrm{~km}^{2}$ to $764.50 \mathrm{~km}^{2}\left(184.95 \mathrm{~km}^{2}\right.$ increased). Moreover, urban area in 2014 expanded to $54.72 \%$ or more than half of total area of city (Table 2).

Table 2. Comparison of urban area change

\begin{tabular}{|c|c|c|c|c|}
\hline & $\mathbf{1 9 9 3}$ & $\mathbf{1 9 9 9}$ & $\mathbf{2 0 0 6}$ & $\mathbf{2 0 1 4}$ \\
\hline Urban area $\left(\mathrm{km}^{2}\right)$ & 462.40 & 579.55 & 764.50 & 866.39 \\
\hline Urban area $(\%)$ & 29.21 & 36.60 & 48.29 & 54.72 \\
\hline
\end{tabular}

Comparison of urban area in Bangkok Administrative zone (Table 3) shows that central zone had the largest urban area, which reached $89.89 \%$ of total zone area in 2014. Besides, the eastern zone had the less change in urban area with only $40.55 \%$ in 2014.

Table 3. Comparison of percentage of urban area in Bangkok zone

\begin{tabular}{|c|c|c|c|c|}
\hline Bangkok zone & $\mathbf{1 9 9 3}$ & $\mathbf{1 9 9 9}$ & $\mathbf{2 0 0 6}$ & $\mathbf{2 0 1 4}$ \\
\hline Central & 72.33 & 80.12 & 86.19 & 89.89 \\
\hline Southern & 65.92 & 72.36 & 79.31 & 83.70 \\
\hline Northern & 42.14 & 51.94 & 66.06 & 74.86 \\
\hline Eastern & 14.11 & 21.27 & 35.31 & 40.55 \\
\hline North Western & 40.99 & 47.48 & 56.43 & 64.39 \\
\hline South Western & 23.40 & 30.45 & 39.74 & 48.05 \\
\hline
\end{tabular}

The comparison of urban area in Bangkok (Figure 1) displays the character of urban development of Bangkok city, which main part of urban development created along transportation. This type of development was difficult to control, manage and it made rapidly and limitless expansion [5].

\subsection{Analysis of Bangkok Comprehensive Plan}

The Bangkok Comprehensive Plans were formulated and were initiated as a guideline for developing Bangkok city. The plan was established four times and each plan had been in effect for seven years. The First Bangkok Comprehensive Plan was established in 1992 by Department of Public Works and Town \& Country Planning. Thailand government announced a new regulation to give management power to local administration in 1999. Thus, Bangkok Administration decided to publish the First Revision of Bangkok Comprehensive Plan.

The Second Revision of Bangkok Comprehensive Plan (2006) was established to solve problems from the First Revision Plan. However, this plan had a problem in term of enforcement because of the mixed up with another law. In 2012, Thailand faced a great flood and it also affected to Bangkok city. Bangkok Metropolis Administration decided to publish the Third Revision Plan in 2013. The main objectives were improving plan's description, preventing disasters and solving global warming problem. 


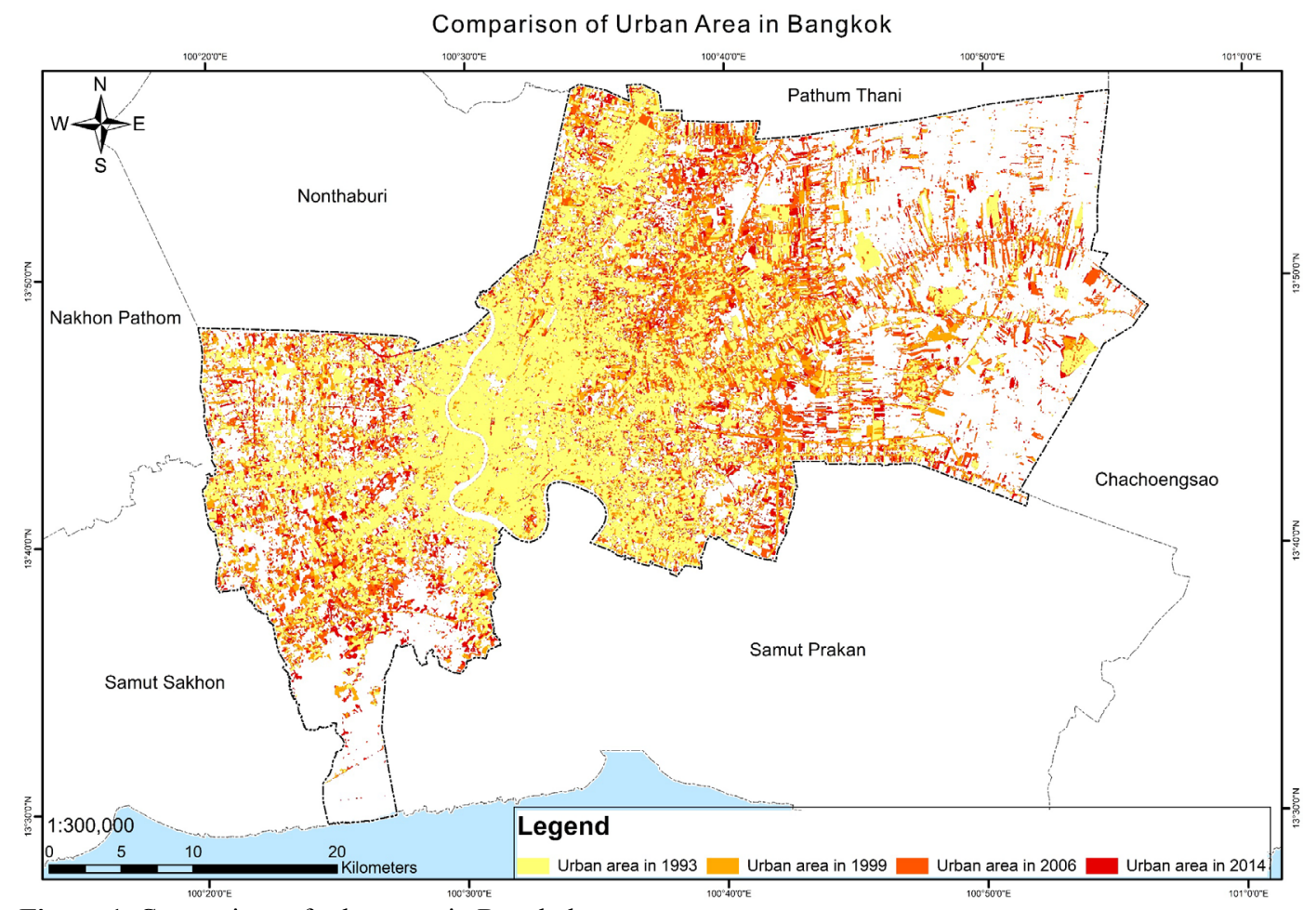

Figure 1. Comparison of urban area in Bangkok

Land Use Zoning Plan of Bangkok comprehensive plan was divided into four main groups: residential zone, commercial zone, industrial zone and rural and agricultural zone. The expected residential zone decreased from $760.92 \mathrm{~km}^{2}$ (1992) to $695.57 \mathrm{~km}^{2}$ (2013). Rural and agricultural zone decreased from $674.20 \mathrm{~km}^{2}$ (1992) to $617.41 \mathrm{~km}^{2}$ (2013). Industrial zone decreased from $19.06 \mathrm{~km}^{2}$ (1992) to $14.08 \mathrm{~km}^{2}$ (2013). While, commercial zone increased from $27.15 \mathrm{~km}^{2}$ (1992) to $50.86 \mathrm{~km}^{2}$ (2013) (Figure 2).

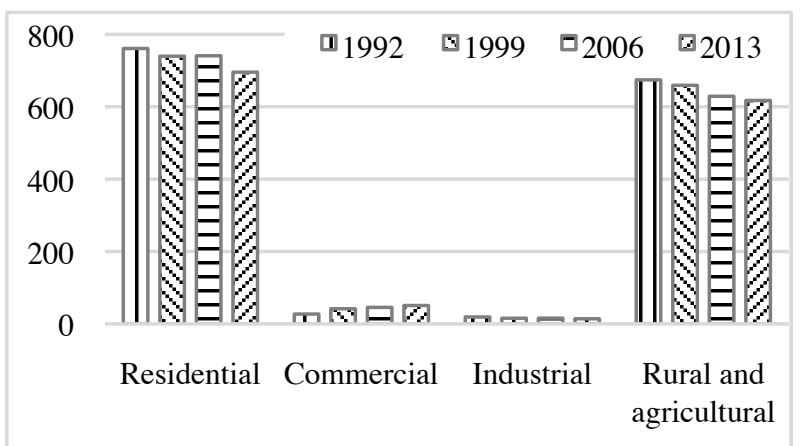

Figure 2. Comparison of land use zoning plan

\subsection{Analysis of urban area and Bangkok Comprehensive Plan and suggest the solution to city planning problems solving}

The population of Bangkok increased from 5.56 million in 1992 to 5.69 million in 2014. Gross provincial product (GPP) increased from 1.15 million (bath) in 1992 to 3.92 million (bath) in 2013. From the prediction of Department of city planning [6] show that in 2030 population will increase to 6.23 million and GPP will increase to 4.21 million (bath) (Figure 3).

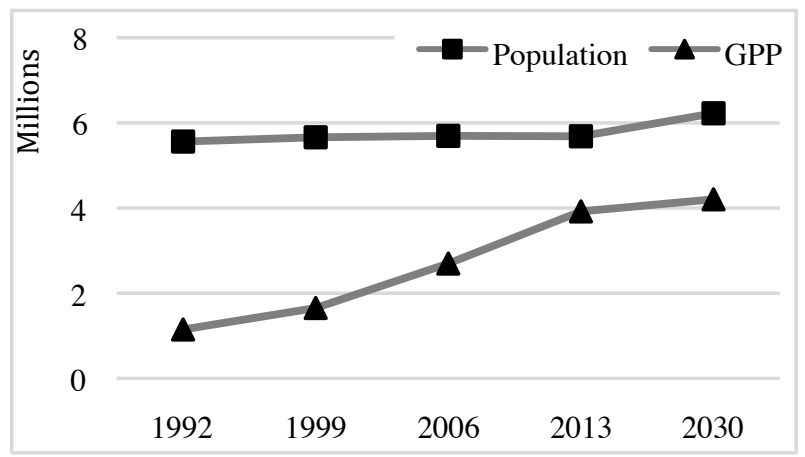

Figure 3. Population and GPP of Bangkok

Urban area expanded $117.15 \mathrm{~km}^{2}\left(19.53 \mathrm{~km}^{2} /\right.$ year $)$ from 1992 to $1999,184.95 \mathrm{~km}^{2}\left(26.42 \mathrm{~km}^{2} /\right.$ year $)$ from 1999 to 2006 and $101.89 \mathrm{~km}^{2}\left(12.74 \mathrm{~km}^{2} /\right.$ year $)$ from 2006 to 2013 (Table 4).

Table 4. Average rate of urban growth in Bangkok

\begin{tabular}{|c|c|c|c|}
\hline & 1992-1999 & 1999-2006 & $\mathbf{2 0 0 6 - 2 0 1 3}$ \\
\hline Area change $\left(\mathrm{km}^{2}\right)$ & 117.15 & 184.95 & 101.89 \\
\hline Average rate $\left(\mathrm{km}^{2} / \mathrm{y}\right)$ & 19.53 & 26.42 & 12.74 \\
\hline
\end{tabular}

Comparison of existing urban area with the expectation area from land use zoning plan shows the increased of urban area in residential zone from 300.89 $\mathrm{km}^{2}$ (1992) to $481.54 \mathrm{~km}^{2}$ (2013). In the other hand, urban area in rural and agricultural zone also increased from $64.30 \mathrm{~km}^{2}$ (1992) to $160.37 \mathrm{~km}^{2}$ (2013) (Figure 4). 


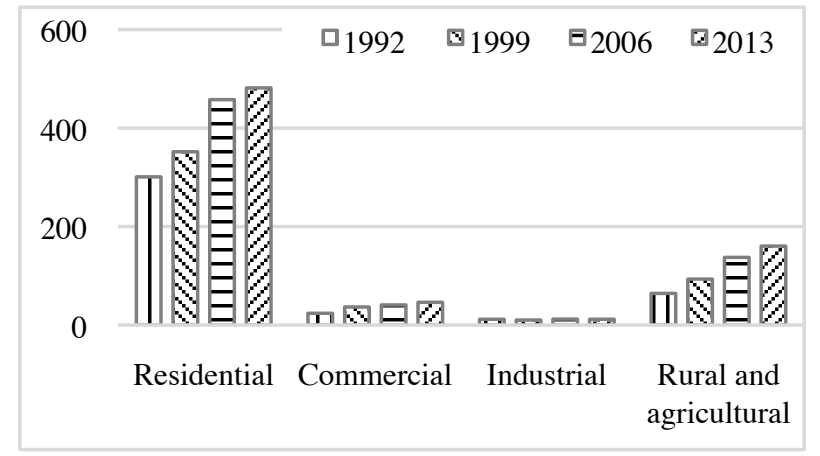

Figure 4. Comparison of urban area in land use zone

In 2015, ASEAN Economic Community (AEC) was formed and Bangkok aimed at developing city to be center of AEC region. Moreover, population and economics of Bangkok in 2030 was predicted that it will grow continuously. From the cause of urban growth showed that population growth and economic growth will create demand for new housing or urban expansion.

So, Bangkok has to develop the city to support the activities from AEC that will occur in the future. At the same time, Bangkok has to control the development of urban areas in residential zone and stop the expansion of urban areas in rural and agricultural zone. From the beginning, rural and agricultural zone was designed as green zones to control flooding. However, it had been rapidly changed into urban area.

From the study of urban planning system of Japan, Area Division System, which city planning area was classified into urbanization promotion area and urbanization control area. This system can prevent disorderly urbanization and control the expansion of urban area. And, the development of urban area, Bangkok should support districts to establish district plan. The district plan can develop and maintain a good urban area that matches the characteristics of different district, for example, to detailed district urbanization, to preserve the environment and to determine layout of public facilities [4].

\section{Conclusion}

This study applied urban area extraction to study urban area in Bangkok city by using BUI and MNDWI and analyzed Bangkok Comprehensive Plan with existing urban area to suggested solutions of city planning problems. The results of this study revealed three main results:

(1) Urban area in Bangkok increased from 462.40 $\mathrm{km}^{2}$ in 1993 to $866.39 \mathrm{~km}^{2}$ in 2014 or $403.99 \mathrm{~km}^{2}$ increased over the past 21 years, which the central zone had the largest urban areas and the eastern zone had the smallest urban areas. The development character of Bangkok was the main part of urban area create along transportation, which it was difficult to manage development and it made rapidly and limitless expansion.

(2) The Bangkok Comprehensive Plans were established four times since 1992. Residential zone and rural and agricultural zone were the main zones of the Land Use Zoning Plan. Residential zone decreased from $760.92 \mathrm{~km}^{2}$ (1992) to $695.57 \mathrm{~km}^{2}$ (2013) because of commercial zone and transportation development. While rural and agricultural zone decreased from $674.20 \mathrm{~km}^{2}$ (1992) to $617.41 \mathrm{~km}^{2}$ (2013) due to residential area expansion.

(3) Bangkok aimed at developing city to be center of AEC region. Population growth and economic growth in Bangkok will create demand for new housing. Moreover, the comparison of extracted urban area with expected land use zoning showed that urban area in residential zone increased from $300.89 \mathrm{~km}^{2}$ (1992) to $481.54 \mathrm{~km}^{2}$ (2013). Urban area in rural and agricultural zone also increased from $64.30 \mathrm{~km}^{2}$ (1992) to $160.37 \mathrm{~km}^{2}$ (2013).

So, Bangkok has to develop the city to support the activities, control urban areas development and stop urban areas expansion. Area Division System from urban planning system of Japan can prevent disorderly urbanization and control the expansion of urban area. Furthermore, Bangkok should support district to plan the district plan, which the plan can control district urbanization, conserve the environment and develop public facilities.

\section{References}

1. B. Basudeb, Analysis of Urban Growth and Sprawl from Remote Sensing Data (Online) Available at: http://www.springer.com/978-3-642-05298-9

2. C. He, P. Shi, D. Xei, Y. Zhao, Remote Sensing Letters 1, 213-221 (2010)

3. A. J. Lee, S. S. Lee, K.H. Chi, Korean Journal of Remote Sensing 27, 637-651 (2011)

4. Ministry of Land, Infrastructure and Transport, Introduction of Urban Land Use Planning System in Japan (Online) Available at:

http://www.mlit.go.jp/common/000234477.pdf

5. C. Nurat, Urban structure in Samut Prakarn province adjacent periphery area of Bangkok metropolitan, Thailand (2010)

6. Department of city planning, Bangkok Comprehensive Plan 2013 (Online) Available at: http://www.mlit.go.jp/common/000234477.pdf

7. N. Sumpaongern, The problems of acheiving the objectives of the Bangkok Comprehensive Plan (Online) Available at:

http://203.131.219.242/cdm/compoundobject/collection/t hesis/id/26200/rec/1

8. Y. Zha, J. Gao, S. Ni, International Journal of Remote Sensing 24, 583-594 (2003) 